\title{
Estimating the Allele-Specific Expression of SNVs From 10x Genomics Single-Cell RNA-Sequencing Data
}

\author{
Prashant N. M. ${ }^{1, \dagger}{ }^{\dagger}$ Hongyu Liu ${ }^{1,2, \dagger}$, Pavlos Bousounis ${ }^{1}$, Liam Spurr ${ }^{1,3,4}$, Nawaf Alomran ${ }^{1}$, \\ Helen Ibeawuchi ${ }^{1}{ }^{1}$, Justin Sein ${ }^{1}$, Dacian Reece-Stremtan ${ }^{5}$ and Anelia Horvath ${ }^{1,6,7, *(\mathbb{C})}$ \\ 1 McCormick Genomics and Proteomics Center, School of Medicine and Health Sciences, The George \\ Washington University, Washington, DC 20037, USA; pnm27@gwmail.gwu.edu (P.N.M.); \\ hliu5259@gwu.edu (H.L.); pdbous@gwu.edu (P.B.); lspurr@broadinstitute.org (L.S.); \\ naa71@georgetown.edu (N.A.); hibeawuchi@gwmail.gwu.edu (H.I.); jsein@gwu.edu (J.S.) \\ 2 Chinese Medicine Toxicological Laboratory, Institute of Traditional Chinese Medicine, Heilongjiang \\ University of Chinese Medicine, Harbin 150040, China \\ 3 Department of Medical Oncology, Dana-Farber Cancer Institute, Boston, MA 02215, USA \\ 4 Cancer Program, The Broad Institute of MIT and Harvard, Cambridge, MA 02142, USA \\ 5 Computer Applications Support Services, School of Medicine and Health Sciences, The George Washington \\ University, Washington, DC 20037, USA; stremtan@gwu.edu \\ 6 Department of Biochemistry and Molecular Medicine, Department of Biostatistics and Bioinformatics, \\ School of Medicine and Health Sciences, George Washington University, Washington, DC 20037, USA \\ 7 Department of Pharmacology and Physiology, School of Medicine and Health Sciences, The George \\ Washington University, Washington, DC 20037, USA \\ * Correspondence: horvatha@gwu.edu \\ $\dagger$ These authors contributed equally to this work.
}

Received: 22 December 2019; Accepted: 19 February 2020; Published: 25 February 2020

\begin{abstract}
With the recent advances in single-cell RNA-sequencing (scRNA-seq) technologies, the estimation of allele expression from single cells is becoming increasingly reliable. Allele expression is both quantitative and dynamic and is an essential component of the genomic interactome. Here, we systematically estimate the allele expression from heterozygous single nucleotide variant (SNV) loci using scRNA-seq data generated on the 10×Genomics Chromium platform. We analyzed 26,640 human adipose-derived mesenchymal stem cells (from three healthy donors), sequenced to an average of $150 \mathrm{~K}$ sequencing reads per cell (more than 4 billion scRNA-seq reads in total). High-quality SNV calls assessed in our study contained approximately $15 \%$ exonic and $>50 \%$ intronic loci. To analyze the allele expression, we estimated the expressed variant allele fraction $\left(\mathrm{VAF}_{\mathrm{RNA}}\right)$ from $\mathrm{SNV}$-aware alignments and analyzed its variance and distribution (mono- and bi-allelic) at different minimum sequencing read thresholds. Our analysis shows that when assessing positions covered by a minimum of three unique sequencing reads, over $50 \%$ of the heterozygous SNVs show bi-allelic expression, while at a threshold of 10 reads, nearly $90 \%$ of the SNVs are bi-allelic. In addition, our analysis demonstrates the feasibility of $\mathrm{scVAF}_{\mathrm{RNA}}$ estimation from current scRNA-seq datasets and shows that the $3^{\prime}$-based library generation protocol of $10 \times$ Genomics scRNA-seq data can be informative in SNV-based studies, including analyses of transcriptional kinetics.
\end{abstract}

Keywords: single cell; $\mathrm{VAF}_{\mathrm{RNA}}$; $\mathrm{sc}-\mathrm{VAF}_{\mathrm{RNA}}$; sc-RNA-seq; monoallelic expression; $\mathrm{SNV}$; genetic variation; RNA-seq; single-cell RNA-sequencing 


\section{Introduction}

In the last several years, single-cell RNA-sequencing (scRNA-seq) has become an accessible platform for genomic studies [1-3]. By enabling cell-level transcriptome analyses, scRNA-seq exhibits a major advantage over the conventional averaged bulk RNA-seq, which is the ability to assess intracellular relationships between molecular features. With the emerging advances in scRNA-seq technologies, estimations of genetic variation from scRNA-seq data are becoming more reliable [4-6]. Recent studies have demonstrated the usefulness of scRNA-seq single nucleotide variant (SNV) assessments for a variety of applications, including random monoallelic expression (RME), transcriptional burst kinetics [7-11], haplotype inference [12], chromosome $X$ inactivation [13,14], genetic heterogeneity in cancer [15-19], aneuploidy [20], quantitative trait loci (QTL) assessments [21], and demultiplexing [22-24].

Genetic variants are traditionally called from DNA and often analyzed and interpreted as discrete genotypes (for diploid organisms, homo- or heterozygous). For expressed loci, genetic variation can also be assessed using RNA-seq data [24-30], by calculating the variant allele fraction $\left(\mathrm{VAF}_{\mathrm{RNA}}=\right.$ $\mathrm{n}_{\mathrm{var}} /\left(\mathrm{n}_{\mathrm{var}}+\mathrm{n}_{\text {ref }}\right)$, where $\mathrm{n}_{\mathrm{var}}$ and $\mathrm{n}_{\text {ref }}$ are the variant and reference read counts, respectively). $\mathrm{VAF}_{\mathrm{RNA}}$ is an informative measure of genetic variation for several reasons. First, compared to the categorical genotypes (DNA allele count of 0,1 , and 2), $\mathrm{VAF}_{\mathrm{RNA}}$ is a continuous measure allowing for precise allele quantitation, which is important for sites where $\mathrm{VAF}_{\mathrm{RNA}}$ does not scale with the DNA allele count. These include loci exhibiting a preferential expression of functional alleles, somatic mutations in cancer, and RNA-editing loci. Second, in contrast to (static) genotypes, $\mathrm{VAF}_{\mathrm{RNA}}$ is dynamic and reflects the actual allele content in the system at a specific moment in time, which aids the assessment of dynamic and progressive processes. Importantly, through primarily reflecting genetic variation, $\mathrm{VAF}_{\mathrm{RNA}}$ is an essential component of the genomic interactome and plays a major role in phenotype formation [31-35].

However, a systematic analysis of the feasibility of $\mathrm{VAF}_{\mathrm{RNA}}$ estimations from $3^{\prime}$-based scRNA-seq libraries and its usefulness for addressing biological questions has not yet been performed. One of the basic biological processes assessed through $\mathrm{VAF}_{\mathrm{RNA}}$ is the prevalence of RME across the diploid mammalian genome. Several recent scRNA-seq studies have described widespread RME in both human and murine models [7-11]. Most of these studies analyzed scRNA-seq data generated on full-length transcript platforms from hundreds of cells.

Here, we demonstrate a pipeline to estimate $\mathrm{VAF}_{\mathrm{RNA}}$ from scRNA-seq data obtained from the $10 \times$ Genomics Chromium platform [36]. We selected this platform due to its growing popularity, along with its (1) high throughput (our analysis includes 26,640 cells obtained from three healthy donors), (2) support for unique molecular identifiers (UMI) for the removal of PCR-related sequencing bias, and (3) high sequencing depth compared to other $10 \times$ Genomics datasets $(\sim 150,000$ sequencing reads per cell). Because $\mathrm{VAF}_{\mathrm{RNA}}$ is sensitive to allele-mapping bias, we used $\mathrm{SNV}$-aware alignments where reads mapped ambiguously due to the variant nucleotide(s) are being removed [37]. To assess the effects of the sequencing depth on the $\mathrm{VAF}_{\mathrm{RNA}}$ estimations, we used minR, which we defined as the number of unique sequencing reads required for the $\mathrm{SNV}$ locus to qualify for $\mathrm{VAF}_{\mathrm{RNA}}$ estimation (i.e., positions covered by fewer reads than $\operatorname{minR}$ were not included in the analysis). From the SNV-aware alignments, we systematically assessed the ability to estimate $\mathrm{VAF}_{\mathrm{RNA}}$ using three different $\operatorname{minR}$ cutoffs: $\operatorname{minR}=$ $3, \operatorname{minR}=5$, and $\operatorname{minR}=10$. We compared outputs across thresholds and individuals, and outlined lists of consistent observations. We also demonstrate an approach for assessing RME, and compare the results from scRNA-seq data generated on the $10 \times$ Genomics Chromium with studies based on different platforms. 


\section{Materials and Methods}

\subsection{Data}

We used publicly available scRNA-seq data from 26,640 human adipose-derived stem cells (ADSC) from three healthy donors (N8, N7, and N5); the scRNA-seq data was generated on the 10×Genomics Chromium v2 platform [36]. The library preparation and sequencing are described in detail elsewhere [36]. Briefly, cells were partitioned using 10× Genomics Single Cell 3' Chips, and barcodes to index cells (14 bp), as well as transcripts (10 bp UMI), were incorporated. The constructed libraries were sequenced on an Illumina NovaSeq 6000 System in a $2 \times 150$ nucleotides (nt) paired-end mode.

\section{2. scRNA-seq Data Processing}

The processing pipeline is shown in Figure 1. First, we extracted the cell barcodes and UMIs using UMI-tools from the pooled (per donor) raw sequencing reads [38].

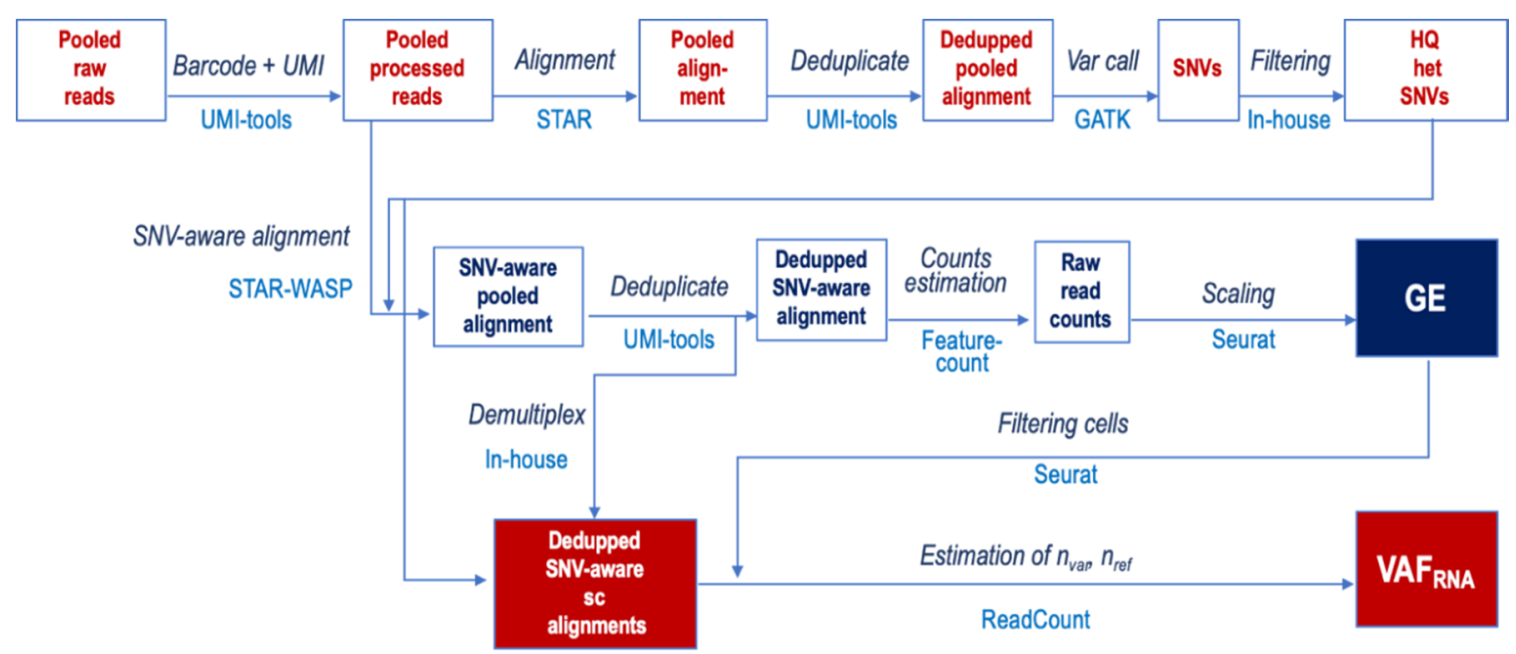

Figure 1. Analytical workflow for an estimation of the variant allele fraction $V_{A F} F_{R N A}$ from single-cell RNA-sequencing (sc-RNA-seq) data.

Next, we aligned the reads to the latest version of the human genome reference (GRCh38, Dec 2013) using STAR v.2.7.3.c [39] in 2-pass mode with transcript annotations from the assembly GRCh38.79. After deduplication with UMI-tools, we called SNVs in the pooled alignments using GATK v.4.1.4.1 [26]. Heterozygous SNVs were selected based on the presence of at least 50 high-quality reads supporting both (reference and alternative) nucleotides in the pooled alignments. From those, we retained heterozygous SNVs meeting the following requirements for further analysis: QUAL (Phred-scaled probability) > 100, MQ (mapping quality) > 60, QD (quality by depth) > 2, and FS (Fisher's exact test estimated strand bias) $=0.000$. In addition, we used annotation (SeattleSeq v.13.00, dbSNP (The Single Nucleotide Polymorphism database) build 153) to remove SNV loci positioned in repetitive or intergenic regions. The SNV lists for each donor were then used as an input for a second, SNV-aware alignment using STAR, this time including the WASP-option [37,39] for the removal of reads mapped ambiguously due to the variant nucleotide. The SNV-aware alignments were deduplicated, keeping the reads with the highest mapping scores using the UMIs, and demultiplexed using the cell barcodes. Raw gene counts were estimated using featureCount [40], after which they were normalized and scaled using Seurat v.3.0 [41]. These gene counts were then employed to remove cells with low-quality data, defined as $<3000$ detected genes or a mitochondrial gene expression higher than $6 \%$ of the total gene expression. The before- and after-filtering distributions of genes and RNA-seq reads are shown in Figure 2. 


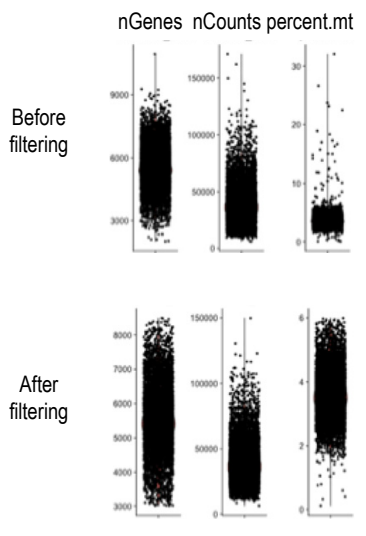

N8
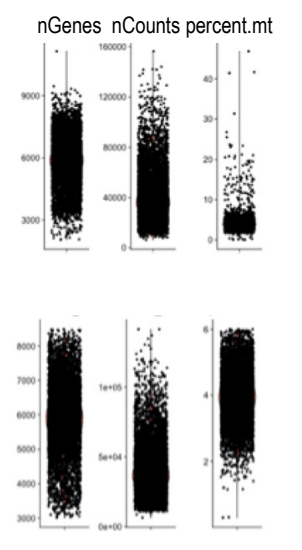

N7
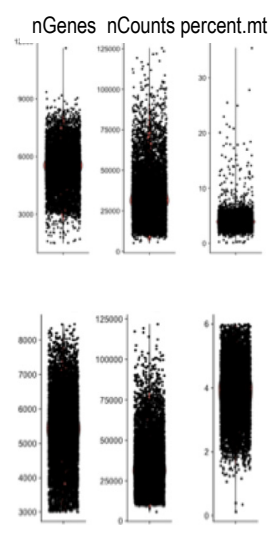

N5

Figure 2. Number of genes, number of sequencing reads, and percent of mitochondrial genes for N8, N7, and N5 before (top) and after (bottom) the filtering out of cells with low-quality data.

We estimated $\mathrm{VAF}_{\mathrm{RNA}}$ from the individual alignments of cells with high-quality data using ReadCounts [31]: $V_{A F} F_{R N A}=n_{v a r} /\left(n_{v a r}+n_{\text {ref }}\right)$, where $n_{v a r}$ and $n_{\text {ref }}$ are the variant and reference read counts, respectively. Next, we performed analyses of $\mathrm{VAF}_{\mathrm{RNA}}$ estimations obtained at three different cutoffs for the required number of reads $(\min R): \min R=10, \min R=5$, and $\min R=3$. For each analysis, $\min R$ was kept constant across the genome, and positions covered by fewer reads than minR were not included in the analysis.

\section{Results}

\subsection{Overall Findings}

The numbers of individual single cells with high-quality data retained for further analysis were 9115,8125 , and 8533 for N8, N7, and N5, respectively. From these cells, we estimated VAF RNA in $50,532 \mathrm{SNV}$ genomic positions in N8, 61,407 in N7, and 38,822 in N5, which were the number of genomic positions retained after filtering for heterozygosity, the quality of the cell, and the position in intragenic non-repetitive regions. To support multi-cell estimations, we only retained positions for which $\mathrm{VAF}_{\text {RNA }}$ was estimated in a minimum of 10 individual cells for statistical analysis. Accordingly, unless otherwise indicated, the hereafter presented analyses are assessments from a minimum of 10 cells (per donor). For $\operatorname{minR}=10$, the absolute number of these positions was 366, 431, and 277 for N8, N7, and N5, respectively. This number was approximately 4-fold higher for positions assessed at minR $=5$ and up to 20 -fold higher for positions at $\operatorname{minR}=3$; the outputs are summarized in Table 1 . We note that the relaxed thresholds are inclusive of the more stringent ones (i.e., $\min R=5$ loci include the loci at $\operatorname{minR}=10$, etc.). Of note, between $6 \%$ and $14 \%$ of all captured SNVs have been previously associated with a clinical phenotype or highlighted by genome-wide association studies (GWAS) analyses (See Table 1).

Table 1. Summary statistics for the scRNA-seq data of the three ADSC samples. We estimated the number of single nucleotide variant (SNV) loci covered in at least 10 individual cells (per donor) with different thresholds for the minimum number of unique reads (minR), and from those, the number of SNVs associated with a phenotype (phenotype and clinical associations were extracted via SeattleSeq database annotation (v13, dbSNP build 153)).

\begin{tabular}{|c|c|c|c|c|c|c|c|c|c|c|c|}
\hline \multirow{2}{*}{ Sample } & \multirow{2}{*}{ N Cells } & \multirow{2}{*}{ N Reads } & \multirow{2}{*}{$\begin{array}{c}\text { Mean } \\
\text { Reads/Cell }\end{array}$} & \multirow{2}{*}{$\begin{array}{l}\text { Median } \\
\text { Genes/Cell }\end{array}$} & \multirow{2}{*}{$\begin{array}{l}\text { N Cells Post } \\
\text { Filtering }\end{array}$} & \multicolumn{3}{|c|}{ N Het SNVs (min 10 cells) } & \multicolumn{3}{|c|}{$\begin{array}{c}\text { N SNVs With } \\
\text { Phenotype/Clinics }\end{array}$} \\
\hline & & & & & & $\min _{10}$ & $\min R 5$ & $\min R 3$ & $\begin{array}{c}\min R \\
10\end{array}$ & $\min R 5$ & $\min R 3$ \\
\hline N7 & 8478 & $1,579,342,505$ & 186,287 & 6049 & 8125 & 431 & 1,994 & 9032 & 57 & 184 & 568 \\
\hline N5 & 8906 & $1,071,156,174$ & 120,273 & 5439 & 8533 & 277 & 1,134 & 5357 & 23 & 134 & 422 \\
\hline
\end{tabular}


Overall, our analysis shows that the analyzed scRNA-seq datasets generated on the 10x Genomics platform contain a considerable number of expressed SNVs covered by at least three unique sequencing reads. At all depth thresholds, approximately $10 \%$ of the SNVs have been associated with (or assessed for an association with) a phenotype, which indicates that $10 \times$ Genomics data can be used in studies examining the functionality of genetic variants.

\subsection{Position-Based SNVs Annotation}

To assess the distribution of SNVs in regard to their position in the gene and predicted functionality, we annotated the SNVs via SeattleSeq (v13, dbSNP build 153); the distribution of functional annotations at each of the three thresholds is shown in Figure 3.

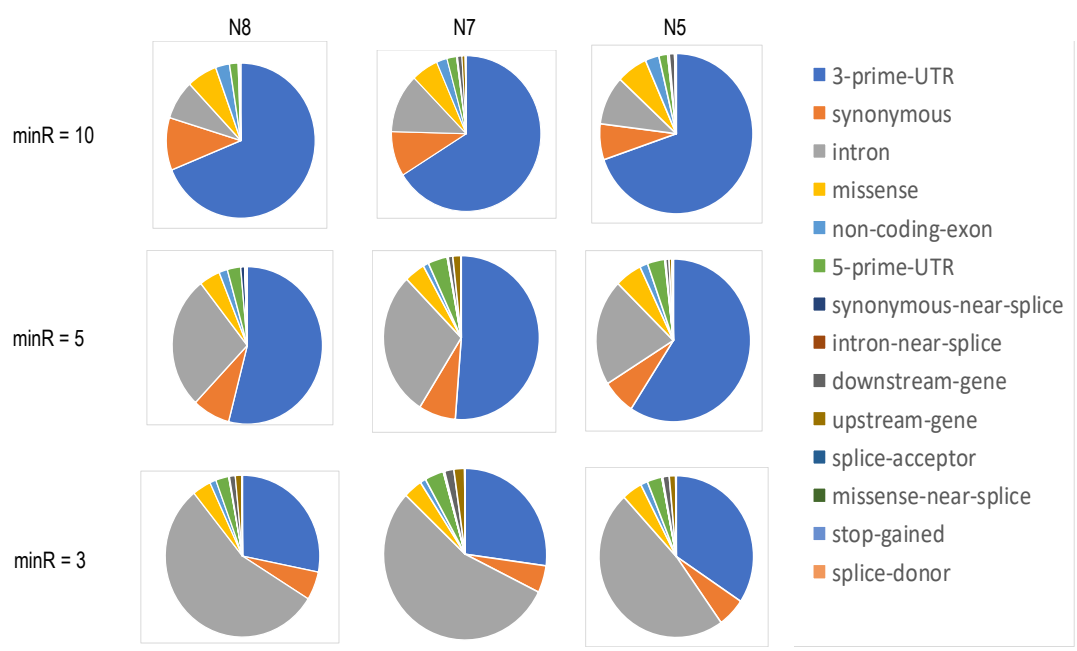

Figure 3. Functional annotation (based on the position in regard to the harboring genes) of SNVs captured by the $10 \times$ Genomics platform with different required minimal counts of unique sequencing reads. At $\operatorname{minR}=5$, over $45 \%$ of the SNVs are positioned downstream of the $3^{\prime}$-UTR regions.

At $\operatorname{minR}=10$, close to three-quarters of the captured SNVs were positioned in the $3^{\prime}$-UTRs of the transcripts, while at $\min R=5$, this proportion decreased to slightly over $50 \%$. At $\operatorname{minR}=3$, approximately a quarter of the captured SNVs resided in the $3^{\prime} \mathrm{UTR}$, while the intronic SNVs increased in proportion to more than $50 \%$. At all thresholds, over $15 \%$ of the SNVs were exonic. The complete annotations are shown in Supplementary Tables S1-S3.

Our position-based SNV analysis shows that, as expected from a 3'-based platform, the largest proportion of called SNVs reside in the $3^{\prime} \mathrm{UTR}$. Of note, this percentage varies inversely with minR. If we exclude technical factors (including erroneous priming during the library preparation), this observation may indicate a low-level expression of transcripts with alternative polyadenylation sites. Importantly, we also observed a substantial percentage of SNVs located in non-3'UTR gene regions (including exons), which indicates that $10 \times$ Genomics scRNA-seq data can be used for an analysis of SNVs from different functional categories.

\subsection{Allele Expression from Single Cells at an SNV Level}

To assess the allele expression from single cells, we analyzed all SNV loci covered with the required number of sequencing reads ( $\operatorname{minR}=10,5$, and 3 ) in at least 10 individual cells. For each SNV locus, we computed a number of $\mathrm{VAF}_{\mathrm{RNA}}$ statistics, including the mean, median, and percentage of mono- and bi-allelic expressing cells (see also Supplementary Tables S1-S3). At all thresholds, the distributions of the $V_{A F} F_{R N A}$ mean and median values were generally symmetrical in regard to the $V_{A F} F_{R N A}$ scale (Supplementary Figure S1). Additionally, at all thresholds, more than half of the VAF estimations were in the range of $0.2<\mathrm{VAF}_{\mathrm{RNA}}<0.8$, corresponding to bi-allelic expression (Table 2). Specifically, 
$\mathrm{VAF}_{\mathrm{RNA}}$ obtained at $\operatorname{minR}=3$ corresponded to bi-allelic expression for over $50 \%$ of the estimations, and this proportion increased to approximately $90 \%$ when confining the analysis to $\mathrm{VAF}_{\mathrm{RNA}}$ estimated at $\min R=10$.

Table 2. Percent of mono- and bi-allelic expression of SNVs covered with different required minimum counts of sequencing reads. *Predominantly monoallelic expression is inclusive of strict monoallelic expression.

\begin{tabular}{|c|c|c|c|c|c|c|c|c|c|}
\hline \multirow[t]{2}{*}{ Sample } & \multicolumn{3}{|c|}{$\begin{array}{l}\% \text { Strictly Monoallelic } \\
\text { VAF }_{\text {RNA }}=0 \text { or } 1\end{array}$} & \multicolumn{3}{|c|}{$\begin{array}{l}\% \text { Predominantly Monoallelic }^{*} \\
\text { VAF }_{\text {RNA }}=0-0.2 \text { or } 0.8-1\end{array}$} & \multicolumn{3}{|c|}{$\begin{array}{c}\% \text { Biallelic } \\
\text { VAF }_{\text {RNA }}=0.2-0.8\end{array}$} \\
\hline & $\min R 10$ & $\min R 5$ & $\min R 3$ & $\min R 10$ & $\min R 5$ & $\min R 3$ & $\min R 10$ & $\min R 5$ & $\min R 3$ \\
\hline N8 & 4.4 & 15.1 & 38.2 & 16.1 & 30.6 & 45.5 & 83.9 & 69.4 & 54.5 \\
\hline N7 & 2.9 & 15.8 & 41.3 & 13.1 & 30.3 & 47.9 & 86.9 & 69.7 & 52.1 \\
\hline N5 & 2.4 & 12.5 & 35.9 & 10 & 26.1 & 42.0 & 90 & 76.9 & 58.0 \\
\hline
\end{tabular}

The distribution of $\mathrm{scVAF}_{\mathrm{RNA}}$ estimations at $\operatorname{minR}=10,5$, and 3 for all heterozygous $\mathrm{SNV}$ in corresponding samples is shown in Figure 4; the histograms include bins for strictly monoallelic expression, defined as $\mathrm{VAF}_{\mathrm{RNA}}$ values of 0 and 1 . Markedly, the data obtained using different minR cutoffs resulted in different $\mathrm{scVAF}_{\mathrm{RNA}}$ distributions. At $\operatorname{minR}=3$, the $\mathrm{VAF}_{\mathrm{RNA}}$ distribution showed a considerable proportion of calls corresponding to monoallelic expression. These monoallelic calls may result from both the stochasticity of sampling, which impacts positions covered by a few reads, and RME, reported previously in single-cell studies [7-11]. At $\min R=5$, strictly monoallelic $\mathrm{VAF}_{\mathrm{RNA}}$ estimations represented less than half of those with $\mathrm{VAF}_{\mathrm{RNA}}=0.5 \pm 0.1$, and decreased in proportion to below $5 \%$ at $\operatorname{minR}=10$.

Next, we analyzed the data per SNV; $\mathrm{VAF}_{\mathrm{RNA}}$ distributions for all the SNVs (genome-wide) assessed from a minimum of 1000 cells are plotted in Figure 5 and Supplementary Figure S2. Aligned with the above observations, at $\operatorname{minR}=10$, the majority of $\mathrm{SNV}$ positions had a substantial proportion of cells with $\mathrm{VAF}_{\mathrm{RNA}}$ estimations between 0.2 and 0.8 ; this proportion gradually decreased at lower thresholds.

Overall, our results show that the $\mathrm{VAF}_{\mathrm{RNA}}$ distribution depends on the minimum number of reads required for an SNV to qualify for inclusion in the analysis. When we include only positions covered by a high number of reads (i.e., 10), the vast majority of $\mathrm{VAF}_{\mathrm{RNA}}$ estimations suggest bi-allelic expression; these analyses are confined to a relatively low number of SNVs (i.e., hundreds of SNVs per sample estimated in at least 10 cells). Lowering the minR naturally results in a higher number of SNVs; in this larger group, we observe higher rates of monoallelic calls. Because at low minR stochasticity of sampling can affect the $\mathrm{VAF}_{\mathrm{RNA}}$ estimations, the observed high rate of monoallelic $\mathrm{VAF}_{\mathrm{RNA}}$ calls at $\min R=3$ could be a result of both technical and biological factors. To assess the effects of technical factors on our analysis, we estimated the consistency of the $\mathrm{VAF}_{\mathrm{RNA}}$ measurements from multiple SNV loci of the same gene, and across the three different samples; we also compared the findings with those from previous scRNA-seq studies (Section 3.4 below). 


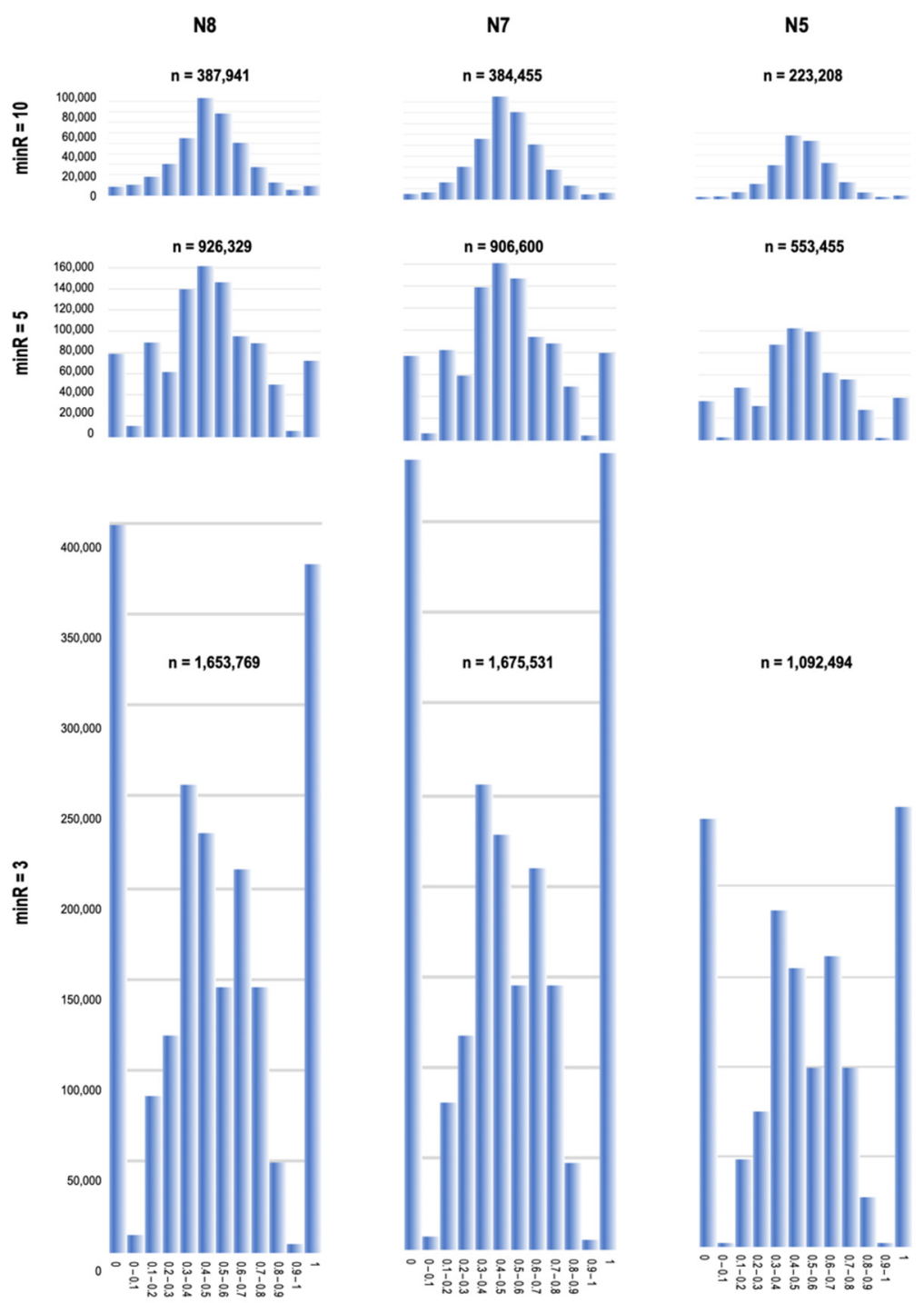

Figure 4. Histograms representing the distribution of $\mathrm{scVAF}_{\mathrm{RNA}}$ at $\min \mathrm{R}=10$ (top), $\min \mathrm{R}=5$ (middle), and $\operatorname{minR}=3$ (bottom) for all the heterozygous SNVs in N8, N7, and N5. The bin width (x-axis) is 0.1 ; bin intervals are indicated in the middle of each plot. The $y$-axes show the numbers of $V_{A F A}$ measurements in the individual cells. The total number of $\mathrm{VAF}_{\mathrm{RNA}}$ estimations ( $\mathrm{n}$, across all the cells per group) is shown at the top of each histogram. The histograms are scaled in regard to the number of cells. Across the entire dataset, at $\operatorname{minR}=10$ and $\min R=5$, the majority of SNVs showed bi-allelic expression centered around a $\mathrm{VAF}_{\mathrm{RNA}}$ value of $0.5\left(0.4<\mathrm{VAF}_{\mathrm{RNA}}<0.6\right)$. In contrast, at $\operatorname{minR}=3$, the majority of SNVs presented with strict monoallelic expression $\left(\mathrm{VAF}_{\mathrm{RNA}}=0\right.$ or 1$)$. The $\mathrm{VAF}_{\mathrm{RNA}}$ distributions showed remarkable similarity across the three individuals (N8, N7, and N5). 


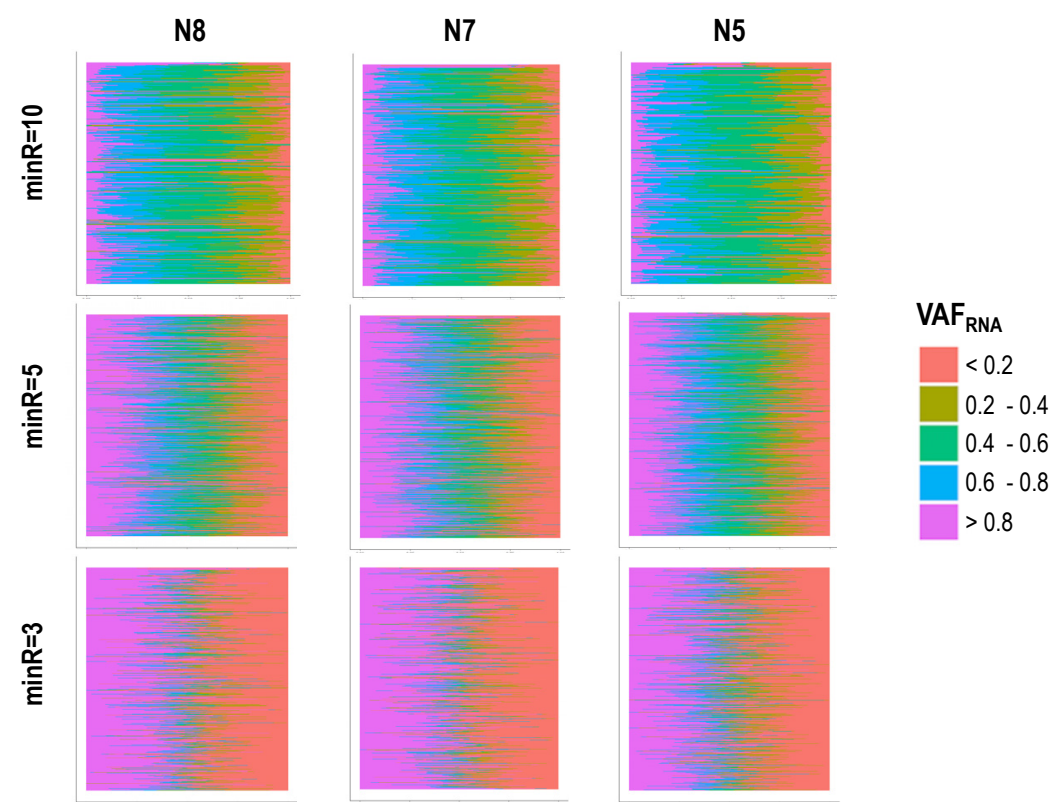

Figure 5. $\mathrm{scVAF}_{\mathrm{RNA}}$ estimated at positions covered by a minimum of 10 sequencing reads (top), 5 sequencing reads (middle), and 3 sequencing reads (bottom), across more than 1000 cells. For the majority of positions, $\mathrm{VAF}_{\mathrm{RNA}}$ showed bi-allelic expression, with a substantial proportion of the $\mathrm{scVAF}_{\mathrm{RNA}}$ estimations in the interval 0.4-0.6.

\subsection{Allelic Expression from Single Cells at a Gene Level}

We analyzed $\mathrm{VAF}_{\mathrm{RNA}}$ at a gene level and compared the findings to those from a major study on allele-specific expression from human scRNA-seq data (Borel et al [9]), using similar definitions for allele-specific expression. Specifically, as monoallelic expression (including RME), we defined SNVs for which fewer than $5 \%$ of the cells displayed a VAF $\mathrm{RNA}_{\mathrm{RN}}$ value between 0.2 and $0.8\left(0.2<\mathrm{VAF}_{\mathrm{RNA}}\right.$ $<0.8$ ). Skewed allelic expression was assigned to SNVs where less than $10 \%$ of the cells expressed one type of allele and the rest expressed either the second allele or both alleles $(<80 \%$ cells with $0.2<$ $\left.\mathrm{VAF}_{\mathrm{RNA}}<0.8\right)$.

We analyzed the genes common to both the dataset used in Borel et al. [9] and our dataset; for our dataset this analysis was performed at all three thresholds. We first assessed the findings at $\min R=$ 10, where 21 genes from our dataset were present among the 60 genes highlighted in Borel et al. [9] (Figure 6, top); all 21 genes showed consistent bi-allelic expression in the two studies. From the above-mentioned 60 genes, autosomal genes with RME were only observed at $\min R=3$ in our dataset, all of which were in complete concordance with Borel et al. [9]. Examples of such genes are shown (Figure 6, bottom), including the strictly monoallelic RAD52. Out of the 12 genes with a reported skewed allelic expression, four were present in our dataset: CNN3, C12orf75, and CCDC80 had a skewed expression, while SPC3 showed symmetrically distributed alleles in both samples where it was detected (Supplementary Table S3).

We next analyzed the concordance of $\mathrm{VAF}_{\mathrm{RNA}}$ estimations between multiple $\mathrm{SNV}$ s residing in the same gene. Markedly, at $\operatorname{minR}=10$, we observed concordant allelic expression for all genes with more than one SNV (see COL1A2, SPARC, CCDC80, and MGST1 in Figure 6). We also observed complete concordance across the three individuals for the SNVs shared between donors; SNVs common for the three donors and assessed from more than 50 cells per donor are shown in Figure 7 (chromosome 1, the rest of the chromosomes showed similar results; see also CAP1, DAD1, SPARC, MGST1, CD44, and STARD7 in Figure 6). 

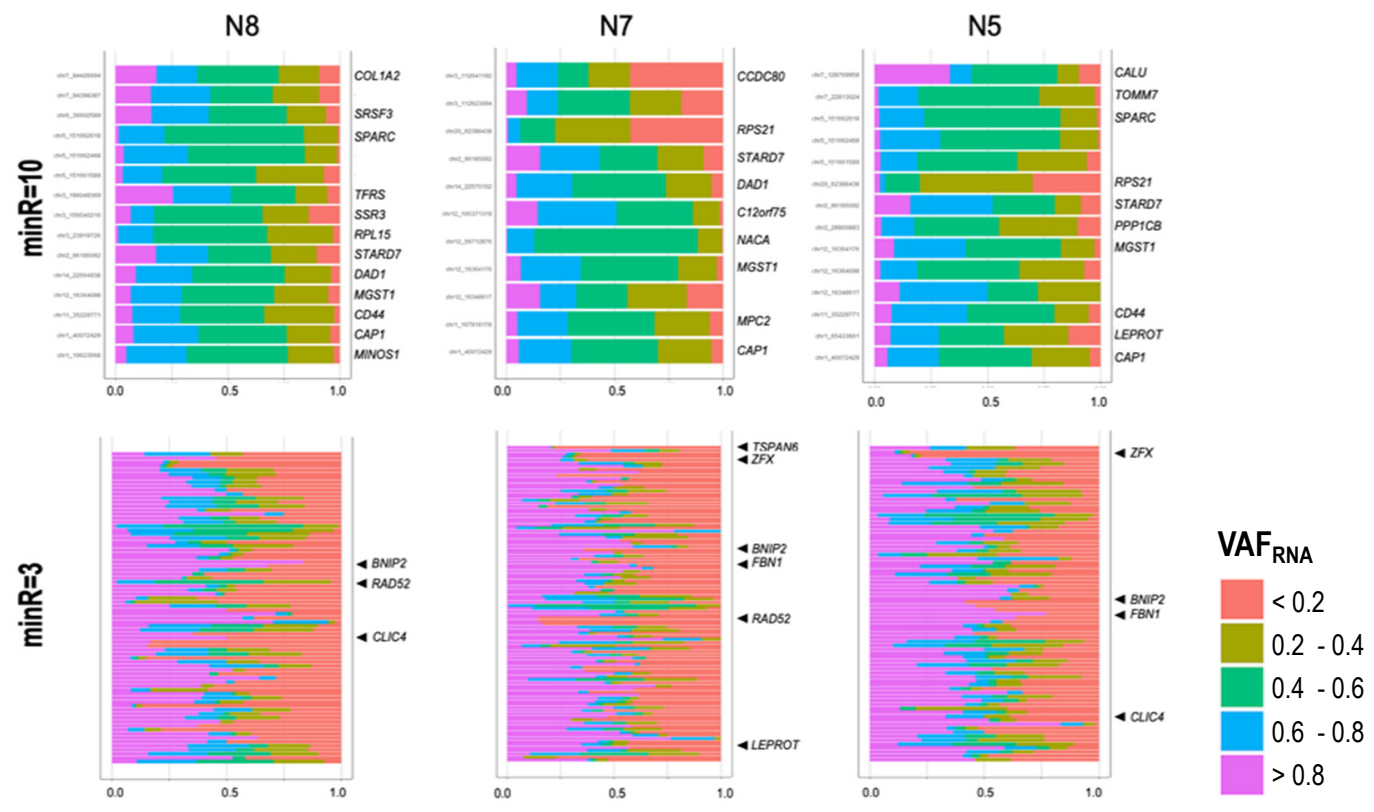

Figure 6. $\mathrm{scVAF}_{\mathrm{RNA}}$ distribution at positions covered by a minimum of 10 sequencing reads (top), and three sequencing reads (bottom), across more than 1500 cells for genes reported by Borel et al. [9]. For the positions with $\operatorname{minR}=10$, no RME was suggested by the $\mathrm{scVAF}_{\mathrm{RNA}}$ distribution for autosomal genes (i.e., for the majority of the estimations $\operatorname{scVAF}_{\mathrm{RNA}}$ values were between 0.2 and 0.8 ), while positions covered with $\operatorname{minR}=3$ showed frequent monoallelic signals $\left(\mathrm{scVAF}_{\mathrm{RNA}}>0.8\right.$ or $\mathrm{scVAF}_{\mathrm{RNA}}<$ 0.2). As expected, chrX shows strong RME patterns (see gene TSPAN6).

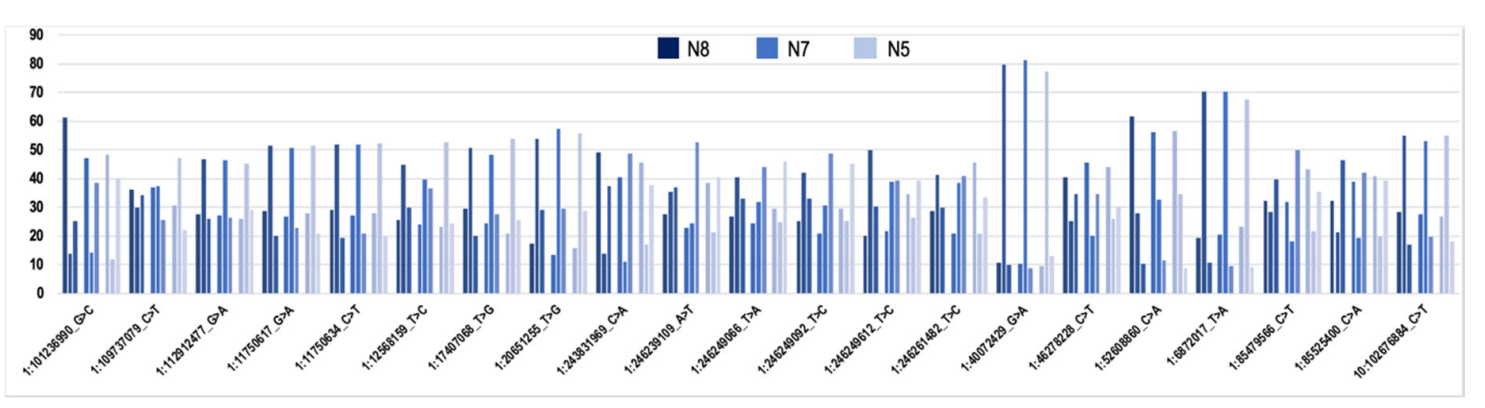

Figure 7. Percentage of cells (y-axis) displaying $\mathrm{VAF}_{\mathrm{RNA}}<0.2$ (for each cluster of three, left), $\mathrm{VAF}_{\mathrm{RNA}}$ between 0.2 and 0.8 (middle), and $\mathrm{VAF}_{\mathrm{RNA}}>0.8$ (right); $\operatorname{minR}=10$. High concordance between the three donors is seen; $\mathrm{SNVs}$ on chromosome 1 are shown, and the results were similar genome-wide.

Next, we assessed mono- and bi-allelic SNV-expression at a gene level across our entire dataset at $\operatorname{minR}=3$. We confined this assessment to SNVs seen in a minimum of 50 cells per sample; $7408 \mathrm{SNVs}$ in 3406 genes were eligible for this analysis across the three donors. Predominant RME (fewer than 5\% of the cells with $\mathrm{VAF}_{\mathrm{RNA}}$ between 0.2 and 0.8 ) was seen in $451 \mathrm{SNVs}$ positioned in 376 genes; from those, $49 \mathrm{SNVs}$ in 42 genes did not have any cells expressing both alleles.

We next assessed the genome-wide consistency of the $\mathrm{VAF}_{\mathrm{RNA}}$ across multiple SNVs from the same gene. To do this, we pooled the SNVs from the three donors together and selected genes with more than three SNVs, each assessed from a minimum of 50 cells per donor; 3922 SNVs in 815 genes were available for this analysis. The first striking observation was that, for most of the genes, intronic SNVs had substantially higher rates of monoallelic calls compared to SNVs in the spliced mRNA (Figure 8). This was evident both at the level of the individual genes (examples shown in Figure 8a), and genome-wide, where the average proportion of cells expressing both alleles $\left(0.2<\operatorname{VAF}_{\mathrm{RNA}}<0.8\right)$ was significantly lower for SNVs positioned in introns, as compared to SNVs in exons and UTRs (Figure 8b, 
chi-square test, $p<0.05$ for all the comparisons at all three thresholds). Within the groups of intronic and non-intronic $\mathrm{SNV}$ s in the same gene, highly consistent $\mathrm{VAF}_{\mathrm{RNA}}$ distributions were observed.

a

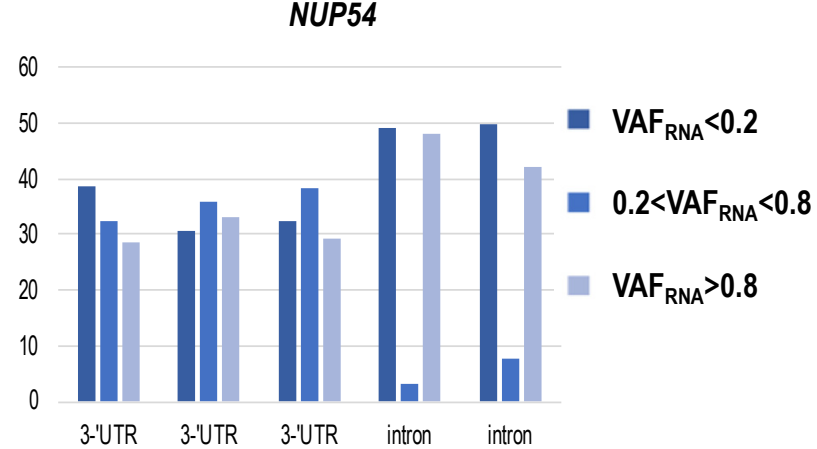

DDR2

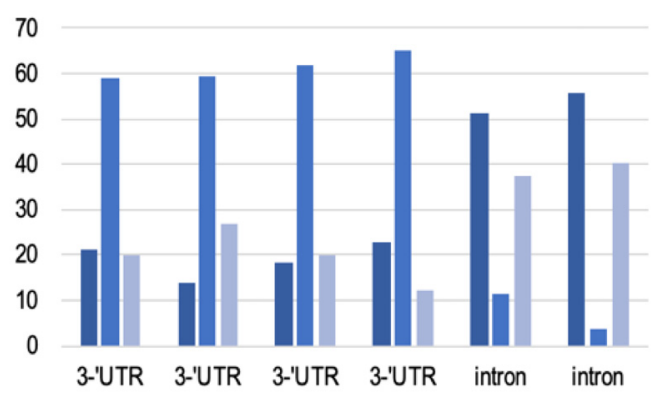

CAPZA2

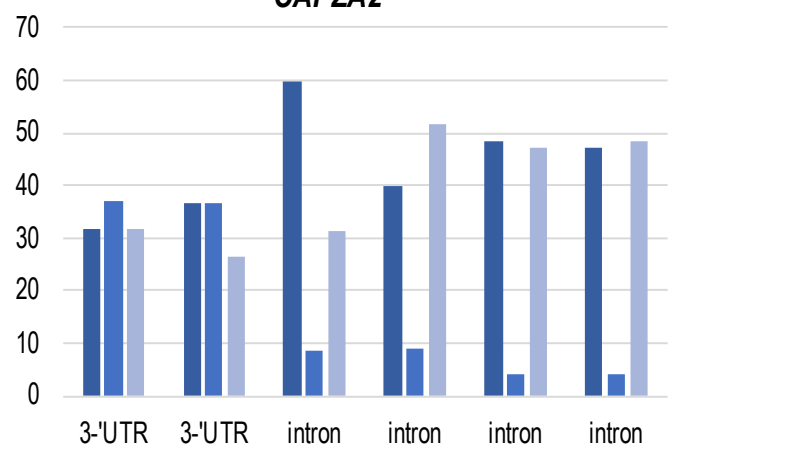

b Proportion cells with bi-allelic expression
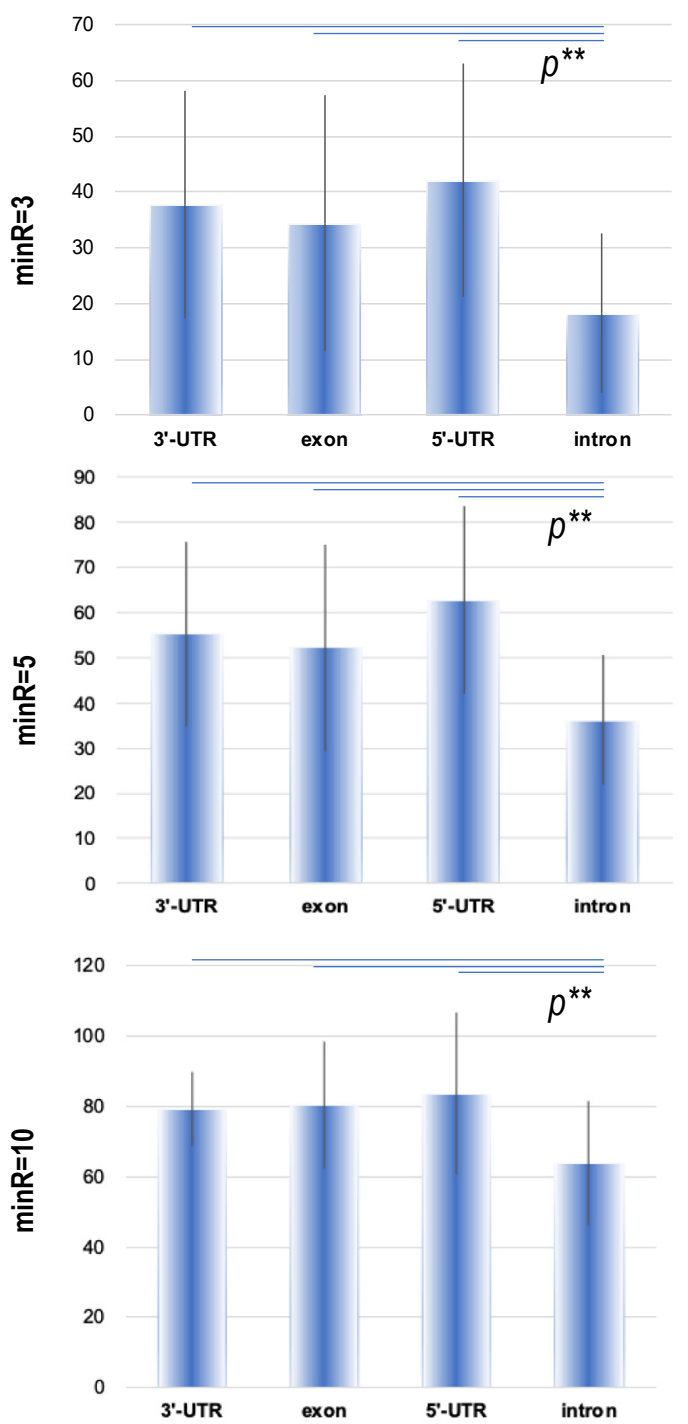

Figure 8. (a) Genes with multiple SNVs positioned in intronic and non-intronic sequences; high percentage of random monoallelic expression (RME) cells $\left(\mathrm{VAF}_{\mathrm{RNA}}<0.2\right.$ or $>0.8, \mathrm{y}$-axis) is obvious. (b) Average percentage of cells (y-axis) with bi-allelic expression across all SNVs in our dataset stratified by position in the gene; SNVs positioned in introns were be-allelic in a lower proportion of cells as compared to all other SNVs.

Our analysis shows highly consistent scRNA-seq $V_{A A} F_{R N A}$ estimations from positions covered by a minimum of 10 unique sequencing reads. Furthermore, multiple SNVs from the same gene showed lower rates of bi-allelic expression from intronic (as compared to non-intronic) SNVs across the three thresholds. However, we note that the latter observation can be affected by the lower counts of intronic (as compared to spliced) RNAseq reads, where a stochasticity of sampling is expected to have a high impact, especially at $\min R=3$. 


\subsection{Considerations for VAF $F_{R N A}$ Estimations From 10× Genomics scRNA-seq Data}

We note several important considerations for $\mathrm{VAF}_{\mathrm{RNA}}$ estimations from scRNA-seq data generated on the $10 \times$ Genomics Chromium Platform. First, as mentioned earlier, this scRNA-seq data is confined to $3^{\prime}$-targeted, relatively short (150nt in our study) sequencing reads. These reads cover only a proportion of the SNVs residing in a transcript, and, for many genes, are likely to not cover a large proportion of the SNVs. Therefore, this data is not suitable for full-length transcript SNV analyses.

Second, observations of monoallelic expression from analyses at low read-count cutoffs can result from both biological (i.e., RME) and technical factors (stochasticity of sampling). Specifically, at $\operatorname{minR}=$ 3 , there is a considerable probability of erroneously assigning a monoallelic status to bi-allelic positions (false positive) due to stochastic factors. We assessed the confidence of the $\mathrm{VAF}_{\mathrm{RNA}}$ estimations by checking for the consistency of observations at the following levels: (1) between multiple SNVs in the same gene, where we observed high concordance (see Figure 8a); (2) across different samples, where we also observed concordant $\mathrm{VAF}_{\mathrm{RNA}}$ estimations (see Figure 7); and (3) with previous estimations [9]. Moreover, to define a $\mathrm{VAF}_{\mathrm{RNA}}$ pattern for a certain $\mathrm{SNV}$, we used information from a minimum of 50 individual cells. Our observation of high rates of monoallelic expression at $\operatorname{minR}=3$ is consistent with a major study on allele-specific expression from human and mouse scRNA-seq data (Deng et al, [10]), which found stable bi-allelic expression for only a few hundred genes, often with housekeeping functions. Furthermore, the authors reported the mean gene expression levels in cells with bi-allelic expression to be approximately two-fold higher than the levels in cells with monoallelic expression. Low read-count cutoffs are generally expected to include a higher number of low-expressed genes. For low-expressed genes, additional technical noise can affect the estimations; therefore, findings at low read cutoffs need to be considered with caution, and validated through additional analyses or experiments.

Related to the above, when selecting minR for an analysis, a major factor to be considered is the balance between the confidence of $\mathrm{VAF}_{\mathrm{RNA}}$ estimation (high $\mathrm{minR}$ ) and the number of analyzed $\mathrm{SNVs}$ (a lower minR will naturally qualify more SNV loci for $\mathrm{VAF}_{\mathrm{RNA}}$ estimations). Our data shows that for current scRNA-seq datasets produced on the $10 \times$ Genomics platform, $\operatorname{minR}=5$ provides a reasonable balance between confidence of the $\mathrm{VAF}_{\mathrm{RNA}}$ estimation and the number of SNVs. For higher confidence, we suggest analyzing the data with more than one $\operatorname{minR}$ in parallel, and assessing the concordance between the more inclusive results at a low $\operatorname{minR}$ and the more confident observations at a high minR.

Furthermore, quality control (QC)-related factors can also affect the estimation of the $\mathrm{VAF}_{\mathrm{RNA}}$ distribution. These include (1) incorrect variant calls (i.e., inaccurate assignment of the presence or absence of an SNV at a given genome position for which $\mathrm{VAF}_{\mathrm{RNA}}$ is to be estimated), (2) an inaccurate assignment of the heterozygous SNV state, and (3) $\mathrm{VAF}_{\mathrm{RNA}}$ estimation. Methods for SNV calls from scRNA-seq data are currently being optimized and benchmarked [4-6]. In this pilot study on the $\mathrm{scVAF}_{\mathrm{RNA}}$ distribution, we only focused on highly confident $\mathrm{SNV}$ calls by retaining for analysis the SNVs (a) with the highest mapping and Phred call quality, (b) positioned outside repetitive regions (known to challenge SNV estimations), and (c) previously validated through dbSNP. In addition, we note that we called SNVs from the pooled (across all the cells per sample) alignments, which helps reduce challenges related to variant calling from scRNA-seq data, and to increase the confidence of heterozygous estimations. Furthermore, when estimating VAF (3), a major factor is the allele-specific mapping bias, which we corrected using WASP [37]. WASP is implemented in the latest versions of the herein used popular aligner STAR [26], which significantly streamlines data processing, especially for datasets with predefined lists of SNV loci of interest (i.e., available genotypes, lists of known SNVs of interest such as RNA-editing sites, dbSNP, etc.).

Finally, the presented pipeline uses RNA-seq data only. While our approach is designed for datasets where matched DNA is not available, one should note that in such a setting, assigning a heterozygosity status for certain SNVs (for example, the SNVs residing in imprinted genes) may be challenging. To confidently assign heterozygosity, we confined our study to bi-allelic SNVs, for which we required a minimum of 50 unique reads supporting each allele from the pooled RNA-seq data per 
donor. By default, this selection excludes heterozygous SNVs with strong non-random monoallelic expression (which would appear as monoallelic in the pooled RNA-seq data). Therefore, the herein presented results need to be considered strictly in the light of this selection. For datasets with available DNA, we recommend the use of genotype calls for assigning a heterozygosity status.

\section{Discussion}

Our analysis includes more than 4 billion RNA-seq reads and over 7.8 million individual scVAF RNA $_{\text {A }}$ estimations, making it, to our knowledge, the largest study on SNV-based allele-specific expression from human scRNA-seq data. We leveraged a large number of cells (over 24K) and a high sequencing depth $\left(150 \mathrm{~K}\right.$ reads per cell) to explore the feasibility of scVAF $_{\mathrm{RNA}}$ estimations, and defined a set of $\mathrm{scVAF}_{\mathrm{RNA}}$ characteristics. Our results show that an SNV assessment of scRNA-seq generated through the $3^{\prime}$-based $10 \times$ Genomics platform can be highly informative for several reasons.

First, annotation of the captured variants supports analyses on variant functionality. As expected, $10 \times$ Genomics scRNA-seq data contains a significant proportion of 3'-UTR variants, which are known to strongly affect both gene expression and splicing [42-46]. In addition, approximately $15 \%$ of the captured SNVs are exonic, and include missense, nonsense, and near-splice variants, many of which can potentially affect the protein structure and function (see Supplementary Tables S1-S3). Importantly, the platform captures a substantial number of intronic SNVs. Intronic sequences are reported in $15 \%-25 \%$ of the RNA-sequencing reads from both bulk and single-cell-based studies [47-50]. ScRNA-seq intronic sequences can be used to estimate the relative abundance of precursor and mature mRNA, thereby assessing the RNA velocity and dynamic cellular processes [47]. Consistent with a major recent study on RNA velocity [47] and models of transcriptional burst kinetics [7], we observed a higher monoallelic expression for intronic SNVs as compared to non-intronic SNVs for a given gene (see Figure 8). Specifically, it was established that at times of increased transcription, unspliced precursors are rapidly produced (often from one of the alleles), and conversely, the proportion of unspliced mRNAs is quickly reduced during periods of lower transcription. Therefore, at any given moment, a single cell is likely to contain more unspliced precursors produced from one of the alleles as compared to the longer-lived spliced mRNAs of the same gene, which are more likely to accumulate both alleles over time. Because the balance of unspliced and spliced mRNA abundance is predictive of the future

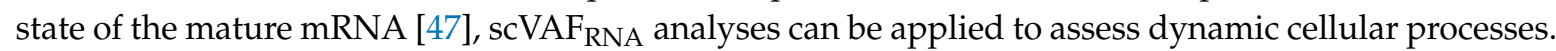
However, for such analyses, it is important to consider the generally lower intronic read counts (as compared to non-intronic) and the related increased probability of erroneously assigning monoallelic calls at bi-allelic positions.

Second, to our knowledge, this is the first study to estimate allele expression from a minimum of 10 unique sequencing reads from scRNA-seq data. Our findings indicate that at such stringency, the majority of autosomal genes show largely symmetric bi-allelic expression. We provide this data $(\operatorname{minR}=10$, Supplementary Table S1), together with the estimations at $\operatorname{minR}=5$ and $\operatorname{minR}=3$ (Supplementary Tables S2 and S3), so that it can be used for analyses of allele-specific expression, both genome-wide and at the level of individual genes of interest.

Third, we have presented a set of characteristics of $\mathrm{VAF}_{\mathrm{RNA}}$ obtained from scRNA-seq data. Several factors facilitate the applicability of $\mathrm{VAF}_{\mathrm{RNA}}$ to assess functional genetic variants (from both bulk and scRNA-seq data). As mentioned earlier, $V_{\text {AFNA }}$ allows for precise allele quantitation, which is particularly important for sites with allele-specific regulation, RNA-editing, and somatic mutations in cancer. Furthermore, $\mathrm{VAF}_{\mathrm{RNA}}$ is dynamic and reflects the actual allele content in the cell at a particular moment in time. In scRNA studies, where the different cells are often in gradual states of progressive processes, $\mathrm{VAF}_{\mathrm{RNA}}$ analyses can be adopted to study lineages and cellular dynamics. Finally, VAF $\mathrm{RNA}$ can be used to study functional SNVs from sets where matched DNA (and, respectively, genotypes) data is not available $[29,30]$. Ultimately, these analyses apply to expressed SNVs and will not capture loci positioned in transcriptionally silent regions. The single-cell resolution of this approach brings further advantages. First, due to the preservation of intracellular relationships between molecular features, 
single-cell analyses facilitate the discovery of correlations between SNVs and other transcriptome features, such as gene expression or splicing. Finally, scRNA-seq projects typically utilize cells with (largely) identical genotypes (i.e., from the same system/individual), thus supplying context for the assessment of SNVs implicated in RNA-specific regulation.

\section{Conclusions}

In conclusion, we have presented a large SNV-focused study on allele expression from scRNA-seq data that addresses three major technical factors known to bias single-cell allelic studies: PCR-related bias, allele-mapping bias, and a low number of sequencing reads. To facilitate similar studies, we have described a step-by-step approach for confident $\mathrm{scVAF}_{\mathrm{RNA}}$ estimations. Our study is largely consistent with existing knowledge, reports findings on previously unassessed genes and SNVs, and supplies datasets for further analyses. In addition, our analysis demonstrates the feasibility of $\mathrm{scVAF}_{\mathrm{RNA}}$ estimation from current scRNA-seq datasets and shows that the $3^{\prime}$-based library generation protocol of $10 \times$ Genomics scRNA-seq data can be highly informative for SNV-based analyses.

Supplementary Materials: The following are available online at http://www.mdpi.com/2073-4425/11/3/240/s1: Figure S1: Mean and median VAF $_{\text {RNA }}$; Figure S2: VAF RNA distributions and cell counts; Table S1: SNV loci minR10 10cells; Table S2: SNV loci minR5 10cells; Table S3: SNV loci minR10 10cells.

Author Contributions: Conceptualization, writing-original draft preparation, and supervision, A.H.; methodology, software, visualization, and writing-review and editing, P.N.M., H.L., P.B., L.S., N.A., H.I., J.S., and D.R.-S. All authors have read and agreed to the published version of the manuscript.

Funding: This work was supported by McCormick Genomic and Proteo-mic Center (MGPC), George Washington University; [MGPC_PG2018 to AH].

Conflicts of Interest: The authors declare no conflicts of interest.

\section{References}

1. Kulkarni, A.; Anderson, A.G.; Merullo, D.P.; Konopka, G. Beyond bulk: A review of single cell transcriptomics methodologies and applications. Curr Opin Biotechnol. 2019, 58, 129-136. [CrossRef] [PubMed]

2. Stuart, T.; Satija, R. Integrative single-cell analysis. Nat. Rev. Genet. 2019, 20, 257-272. [CrossRef]

3. Zafar, H.; Wang, Y.; Nakhleh, L.; Navin, N.; Chen, K. Monovar: Single-nucleotide variant detection in single cells. Nat. Methods. 2016, 13, 505-507. [CrossRef] [PubMed]

4. Schnepp, P.M.; Chen, M.; Keller, E.T.; Zhou, X. SNV identification from single-cell RNA sequencing data. Hum. Mol. Genet. 2019, 28, 3569-3583. [CrossRef] [PubMed]

5. Dong, M.; Jiang, Y. Single-Cell Allele-Specific Gene Expression Analysis. Methods Mol. Biol. 2019, 1935, 155-174. [PubMed]

6. Liu, F.; Zhang, Y.; Zhang, L.; Li, Z.; Fang, Q.; Gao, R.; Zhang, Z. Systematic comparative analysis of single-nucleotide variant detection methods from single-cell RNA sequencing data. Genome Biol 2019, 19, 242. [CrossRef]

7. Larsson, A.J.M.; Johnsson, P.; Hagemann-Jensen, M.; Hartmanis, L.; Faridani, O.R.; Reinius, B.; Segerstolpe, Å; Rivera, C.M.; Ren, B.; Sandberg, R. Genomic encoding of transcriptional burst kinetics. Nature 2019, 565, 251-254. [CrossRef]

8. Kim, J.K.; Marioni, J.C. Inferring the kinetics of stochastic gene expression from single-cell RNA-sequencing data. Genome Biol 2013, 14, R7. [CrossRef]

9. Borel, C.; Ferreira, P.G.; Santoni, F.; Delaneau, O.; Fort, A.; Popadin, K.Y.; Garieri, M.; Falconnet, E.; Ribaux, P.; Guipponi, M.; et al. Biased allelic expression in human primary fibroblast single cells. Am. J. Hum. Genet. 2015, 96, 70-80. [CrossRef]

10. Deng, Q.; Ramsköld, D.; Reinius, B.; Sandberg, R. Single-cell RNA-seq reveals dynamic, random monoallelic gene expression in mammalian cells. Science. 2014, 343, 193-196. [CrossRef]

11. Kim, J.K.; Kolodziejczyk, A.A.; Ilicic, T.; Teichmann, S.A.; Marioni, J.C. Characterizing noise structure in single-cell RNA-seq distinguishes genuine from technical stochastic allelic expression. Nat. Commun. 2015, 6, 8687. [CrossRef] [PubMed] 
12. Edsgärd, D.; Reinius, B.; Sandberg, R. Scphaser: Haplotype inference using single-cell RNA-seq data. Bioinformatics. 2016, 32, 3038-3040. [CrossRef] [PubMed]

13. Moreira de Mello, J.C.; Fernandes, G.R.; Vibranovski, M.D.; Pereira, L.V. Early X chromosome inactivation during human preimplantation development revealed by single-cell RNA-sequencing. Sci Rep. 2017, 7, 10794. [CrossRef] [PubMed]

14. D'Antonio-Chronowska, A.; Donovan, M.K.R.; Greenwald, W.W.; Nguyen, J.P.; Fujita, K.; Hashem, S.; Matsui, H.; Soncin, F.; Parast, M.; Ward, M.C.; et al. Association of Human iPSC Gene Signatures and X Chromosome Dosage with Two Distinct Cardiac Differentiation Trajectories. Stem Cell Reports. 2019, 13, 924-938. [CrossRef] [PubMed]

15. Poirion, O.; Zhu, X.; Ching, T.; Garmire, L.X. Using single nucleotide variations in single-cell RNA-seq to identify subpopulations and genotype-phenotype linkage. Nat. Commun. 2018, 9, 4892. [CrossRef]

16. Vu, T.N.; Nguyen, H.N.; Calza, S.; Kalari, K.R.; Wang, L.; Pawitan, Y. Cell-level somatic mutation detection from single-cell RNA-sequencing. Bioinformatics. 2019. [CrossRef]

17. Rodriguez-Meira, A.; Buck, G.; Clark, S.A.; Povinelli, B.J.; Alcolea, V.; Louka, E.; McGowan, S.; Hamblin, A.; Sousos, N.; Barkas, N.; et al. Unravelling Intratumoral Heterogeneity through High-Sensitivity Single-Cell Mutational Analysis and Parallel RNA Sequencing. Mol. Cell. 2019, 73, 1292-1305. [CrossRef]

18. Reinius, B.; Mold, J.E.; Ramsköld, D.; Deng, Q.; Johnsson, P.; Michaëlsson, J.; Frisén, J.; Sandberg, R. Analysis of allelic expression patterns in clonal somatic cells by single-cell RNA-seq. Nat. Genet. 2016, 48, 1430-1435. [CrossRef]

19. Lee, M.P. Understanding Cancer Through the Lens of Epigenetic Inheritance, Allele-Specific Gene Expression, and High-Throughput Technology. Front Oncol. 2019, 9, 794. [CrossRef]

20. Griffiths, J.A.; Scialdone, A.; Marioni, J.C. Mosaic autosomal aneuploidies are detectable from single-cell RNAseq data. BMC Genomics. 2017, 18, 904. [CrossRef]

21. van der Wijst, M.G.; Brugge, H.; de Vries, D.H.; Deelen, P.; Swertz, M.A.; Franke, L. Single-cell RNA sequencing identifies cell type-specific cis-eQTLs and co-expression QTLs. Nat. Genet. 2018, 50, 493-497. [CrossRef] [PubMed]

22. Huang, Y.; McCarthy, D.J.; Stegle, O. Vireo: Bayesian demultiplexing of pooled single-cell RNA-seq data without genotype reference. Genome Biol. 2019, 20, 273. [CrossRef] [PubMed]

23. Xu, J.; Falconer, C.; Nguyen, Q.; Crawford, J.; McKinnon, B.D.; Mortlock, S.; Senabouth, A.; Andersen, S.; Chiu, H.S.; Jiang, L.; et al. Genotype-free demultiplexing of pooled single-cell RNA-seq. Genome Biol. 2019, 20, 290. [CrossRef] [PubMed]

24. Kang, H.M.; Subramaniam, M.; Targ, S.; Nguyen, M.; Maliskova, L.; McCarthy, E.; Wan, E.; Wong, S.; Byrnes, L.; Lanata, C.M.; et al. Multiplexed droplet single-cell RNA-sequencing using natural genetic variation. Nat. Biotechnol. 2018, 36, 89-94. [CrossRef] [PubMed]

25. Horvath, A.; Pakala, S.B.; Mudvari, P.; Reddy, S.D.; Ohshiro, K.S.; Pires, R.; Fuqua, S.A.; Toi, M.; Costa, L.; Nair, S.S.; et al. Novel insights into breast cancer genetic variance through RNA sequencing. Sci Rep. 2013, 3, 2256. [CrossRef] [PubMed]

26. Van der Auwera, G.A.; Carneiro, M.O.; Hartl, C.; Poplin, R.; Del Angel, G.; Levy-Moonshine, A.; Jordan, T.; Shakir, K.; Roazen, D.; Thibault, J.; et al. From FastQ data to high confidence variant calls: The Genome Analysis Toolkit best practices pipeline. Curr Protoc Bioinformatics. 2013, 43.

27. Deelen, P.; Zhernakova, D.V.; de Haan, M.; van der Sijde, M.; Bonder, M.J.; Karjalainen, J.; van der Velde, K.J.; Abbott, K.M.; Fu, J.; Wijmenga, C.; et al. Calling genotypes from public RNA-sequencing data enables identification of genetic variants that affect gene-expression levels. Genome Med. 2015, 7, 30. [CrossRef]

28. Kravitz, S.N.; Gregg, C. New subtypes of allele-specific epigenetic effects: Implications for brain development, function and disease. Curr Opin Neurobiol. 2019, 59, 69-78. [CrossRef]

29. Spurr, L.; Alomran, N.; Bousounis, P.; Reece-Stremtan, D.; Prashant, N.M.; Liu, H.; Słowiński, P.; Li, M.; Zhang, Q.; Sein, J.; et al. ReQTL: Identifying correlations between expressed SNVs and gene expression using RNA-sequencing data. Bioinformatics. 2019. [CrossRef]

30. Sein, J.; Spurr, L.; Bousounis, P.; Prashant, N.M.; Liu, H.; Alomran, N.; Bernot, J.; Ibeawuchi, H.; Reece-Stremtan, D.; Horvath, A. RsQTL: Correlation of expressed SNVs with splicing using RNA-sequencing data. Bioinformatics 2019. Under Review. 
31. Movassagh, M.; Alomran, N.; Mudvari, P.; Dede, M.; Dede, C.; Kowsari, K.; Restrepo, P.; Cauley, E.; Bahl, S.; Li, M.; et al. RNA2DNAlign: Nucleotide resolution allele asymmetries through quantitative assessment of RNA and DNA paired sequencing data. Nucleic Acids Res. 2016, 44, e161. [CrossRef] [PubMed]

32. Mudvari, P.; Movassagh, M.; Kowsari, K.; Seyfi, A.; Kokkinaki, M.; Edwards, N.J.; Golestaneh, N.; Horvath, A. SNPlice: Variants that modulate Intron retention from RNA-sequencing data. Bioinformatics 2015, 31, 1191-1198. [CrossRef] [PubMed]

33. Restrepo, P.; Movassagh, M.; Alomran, N.; Miller, C.; Li, M.; Trenkov, C.; Manchev, Y.; Bahl, S.; Warnken, S.; Spurr, L.; et al. Overexpressed somatic alleles are enriched in functional elements in Breast Cancer. Sci. Rep. 2017, 7, 8287. [CrossRef] [PubMed]

34. Spurr, L.; Li, M.; Alomran, N.; Zhang, Q.; Restrepo, P.; Movassagh, M.; Trenkov, C.; Tunnessen, N.; Apanasovich, T.; Crandall, K.A.; et al. Systematic pan-cancer analysis of somatic allele frequency. Sci. Rep. 2018, 8, 7735. [CrossRef] [PubMed]

35. Suvà, M.L.; Tirosh, I. Single-Cell RNA Sequencing in Cancer: Lessons Learned and Emerging Challenges. Mol. Cell 2019, 75, 7-12. [CrossRef] [PubMed]

36. Liu, X.; Xiang, Q.; Xu, F.; Huang, J.; Yu, N.; Zhang, Q.; Long, X.; Zhou, Z. Single-cell RNA-seq of cultured human adipose-derived mesenchymal stem cells. Sci. Data. 2019, 6, 190031. [CrossRef]

37. van de Geijn, B.; McVicker, G.; Gilad, Y.; Pritchard, J.K. WASP: Allele-specific software for robust molecular quantitative trait locus discovery. Nat. Methods 2015, 12, 1061-1063. [CrossRef]

38. Smith, T.; Heger, A.; Sudbery, I. UMI-tools: Modeling sequencing errors in Unique Molecular Identifiers to improve quantification accuracy. Genome Res. 2017, 27, 491-499. [CrossRef]

39. Dobin, A.; Davis, C.A.; Schlesinger, F.; Drenkow, J.; Zaleski, C.; Jha, S.; Batut, P.; Chaisson, M.; Gingeras, T.R. STAR: Ultrafast universal RNA-seq aligner. Bioinformatics 2013, 29, 15-21. [CrossRef]

40. Liao, Y.; Smyth, G.K.; Shi, W. Feature counts: An efficient general purpose program for assigning sequence reads to genomic features. Bioinformatics 2014, 30, 923-930. [CrossRef]

41. Butler, A.; Hoffman, P.; Smibert, P.; Papalexi, E.; Satija, R. Integrating single-cell transcriptomic data across different conditions, technologies, and species. Nat. Biotechnol. 2018, 36, 411-420. [CrossRef] [PubMed]

42. Gruber, A.J.; Gypas, F.; Riba, A.; Schmidt, R.; Zavolan, M. Terminal exon characterization with TECtool reveals an abundance of cell-specific isoforms. Nat. Methods. 2018, 15, 832-836. [CrossRef] [PubMed]

43. Kishore, S.; Luber, S.; Zavolan, M. Deciphering the role of RNA-binding proteins in the post-transcriptional control of gene expression. Brief. Funct Genomics. 2010, 9, 391-404. [CrossRef] [PubMed]

44. Hausser, J.; Zavolan, M. Identification and consequences of miRNA-target interactions-beyond repression of gene expression. Nat. Rev. Genet. 2014, 15, 599-612. [CrossRef]

45. Chatterjee, S.; Pal, J.K. Role of $5^{\prime}$ - and $3^{\prime}$-untranslated regions of mRNAs in human diseases. Biol Cell. 2009, 101, 251-262. [CrossRef]

46. Maiti, G.P.; Ghosh, A.; Mondal, P.; Baral, A.; Datta, S.; Samadder, S.; Nayak, S.P.; Chakrabarti, J.; Biswas, J.; Sikdar, N.; et al. SNP rs1049430 in the 3'-UTR of SH3GL2 regulates its expression: Clinical and prognostic implications in head and neck squamous cell carcinoma. Biochim Biophys Acta. 2015, 1852, 1059-1067. [CrossRef]

47. La Manno, G.; Soldatov, R.; Zeisel, A.; Braun, E.; Hochgerner, H.; Petukhov, V.; Lidschreiber, K.; Kastriti, M.E.; Lönnerberg, P.; Furlan, A.; et al. RNA velocity of single cells. Nature. 2018, 560, 494-498. [CrossRef]

48. Picelli, S.; Björklund, Å.K.; Faridani, O.R.; Sagasser, S.; Winberg, G.; Sandberg, R. Smart-seq2 for sensitive full-length transcriptome profiling in single cells. Nat. Methods. 2013, 10, 1096-1098. [CrossRef]

49. Gaidatzis, D.; Burger, L.; Florescu, M.; Stadler, M.B. Analysis of intronic and exonic reads in RNA-seq data characterizes transcriptional and post-transcriptional regulation. Nat. Biotechnol. 2015, 33, 722-729. [CrossRef]

50. Tani, H.; Mizutani, R.; Salam, K.A.; Tano, K.; Ijiri, K.; Wakamatsu, A.; Isogai, T.; Suzuki, Y.; Akimitsu, N. Genome-wide determination of RNA stability reveals hundreds of short-lived noncoding transcripts in mammals. Genome Res. 2012, 22, 947-956. [CrossRef]

(C) 2020 by the authors. Licensee MDPI, Basel, Switzerland. This article is an open access article distributed under the terms and conditions of the Creative Commons Attribution (CC BY) license (http://creativecommons.org/licenses/by/4.0/). 